\title{
Role of L-Type Calcium Channel Modulation in Nonconvulsive Epilepsy in Rats
}

\author{
E. L. J. M. van Luijtelaar, N. Ates, and A. M. L. Coenen \\ NICI, Department of Psychology, University of Nijmegen, Nijmegen, The Netherlands
}

Summary: Old male Wistar rats spontaneously showing hundreds of spike-wave discharges daily were used to investigate the role of calcium ions in nonconvulsive epilepsy. The effects of the L-type calcium channel blocker nimodipine and the L-type channel opener BAY K 8644 on number and duration of these spike-wave discharges were investigated. In rats aged 84-94 weeks standard EEG electrodes were chronically implanted; animals were allowed to recover for 10 days. After a baseline registration, nimodipine $2.2,8.8$, and $35.2 \mathrm{mg} / \mathrm{kg}$ or BAY $\mathrm{K} 8644$ in dosages of $0.12,0.47$, and $1.88 \mathrm{mg} / \mathrm{kg}$ was administered. A control group received the solvent. EEG recordings were made to evaluate drug effects. The highest dose of nimodipine increased the number of spikewave discharges, whereas BAY K 8644 reduced the number of spike-wave discharges dose dependently. The high- est dose of BAY K 8644 also induced fatal convulsions in 3 animals. Our results demonstrate that the L-type calcium antagonist nimodipine facilitates spike-wave discharges and that the L-type calcium agonist BAY K 8644 protects against these discharges, in contrast to previous results suggesting that calcium channel blockers act as antiepileptic drugs (AEDs) and that calcium channel openers act as convulsants. Our results are a further example of the different pharmacologic profile of convulsive and nonconvulsive epilepsy and are also in contrast to what has been described for T-type calcium channel modulation. We therefore propose that modulation of L-type and T-type calcium channels have opposite effects in nonconvulsive epilepsy. Key Words: Absence epilepsyNimodipine-Bay K 8644-L-type calcium channelsSpike-wave discharges-Aged rats.
There are several indications that calcium plays a role in epileptogenesis. During a seizure, the concentration of intracellular calcium ions increases and the extracellular concentration of calcium ions decreases (Heinemann et al., 1977). Crowder and Bradford (1987) and Yaari et al. (1987) also demonstrated involvement of calcium, reporting that antiepileptic drugs (AEDs) such as phenytoin (PHT) and carbamazepine (CBZ) inhibit influx of calcium ions. Finally, the specific antiabsence drugs ethosuximide (ESM) and $\alpha$-methyl- $\alpha$-phenylsuccinimide block a subtype of calcium channel, the T-type, in thalamic neurons (Coulter et al., 1990). Therefore, drugs that block influx of calcium ions into the cells by blocking calcium channels, calcium antagonists, probably have antiepileptic properties (Ashton and Wauquier, 1979; Hoffmeister et al., 1982; Heinemann and Hamon, 1986; Meyer et al., 1987; De Sarro et al., 1988; Speckmann and Walden, 1989; Sills et al., 1994).

Received December 1993; revision accepted March 1994.

Address correspondence and reprint requests to $\mathrm{Dr}$. E. L. J. M. van Luijtelaar at NICI, Department of Psychology, P.O. Box 9104, 6500 HE Nijmegen, The Netherlands.
The role of calcium ions in genetic epilepsy rat models was confirmed by De Sarro et al. (1990), who showed that the calcium channel opener Bay K 8644 facilitates convulsions in sound-induced epilepsy in genetically epilepsy-prone rats (GEPR). Bay K 8644, a dihydropyridine derivative, increases the opening probability of a particular subclass of calcium channels, the L-type channel, thereby promoting voltage-dependent calcium influx (Bernath, 1992). On the other hand, nimodipine also belongs to the class of dihydropyridines, but this centrally active drug acts as a calcium antagonist by blocking the voltage-dependent L-type calcium channels (Meyer et al., 1987; Suzuki and Rogawski, 1989). Spedding and Paoletti (1992) suggest that BAY K 8644 and nimodipine are rather selective for the L-type calcium channels.

Among the many epilepsy models used to evaluate calcium channel modulation, models for generalized absence epilepsy are lacking. We investigated the effects of acute administration of nimodipine and Bay K 8644 on number and mean duration of spontaneously occurring spike-wave discharges in old Wistar rats. Several inbred rat 
strains such as the WAG/Rij strain (van Luijtelaar and Coenen, 1986), but also selection lines such as Strasbourg rats (Vergnes et al., 1982) and outbred strains such as the Wistar and the Sprague Dawley strains, show an age-dependent increase in both the amount of spontaneously occurring spike-wave discharges and in number of affected animals (Coenen et al., 1992). These genetically determined spikewave discharges are accompanied by minor clinical signs (van Luijtelaar and Coenen, 1986) and occur predominantly during passive wakefulness and light slow-wave sleep (SWS) and less during deep SWS and REM sleep (Coenen et al., 1991; Drinkenburg et al., 1991). The spike-wave discharges can be blocked by broad spectrum AEDs such as diazepam (DZP) and valproate (VPA) and also by ESM and trimethadion, but not by AEDs such as CBZ and PHT (Peeters et al., 1988). We report the effects of acute administration of nimodipine and BAY $\mathrm{K}$ 8644 in old Wistar rats, which exhibit several hundred spontaneously occurring spike-wave discharges daily (van Luijtelaar et al., 1994).

\section{METHODS}

Old male random-bred Wistar rats donated by Troponwerke (Cologne, Germany) and originally purchased from Winkelmann (Borchen, Germany) were studied. The rats had no previous drug history. Preoperatively, they were housed in groups and then were singly housed. At operation, they were aged 84-94 weeks and weighed 389-528 g. Animals were maintained on a 12/12-h light/dark regime, with white lights on at $2000 \mathrm{~h}$.

EEG electrodes in the frontal and parietooccipital cortical region with coordinates A 2.0, L 3.5 and A-6.0, L 4.0 respectively, with skull surface flat and bregma zero zero, were permanently implanted under pentobarbital anaesthesia $(60 \mathrm{mg} / \mathrm{kg})$. The ground electrode was placed over the cerebellum. Postoperatively, subjects were allowed to recover for 10 days.

The experiment was performed in freely moving animals during the dark phase of the day and drugs were always administered at $1100 \mathrm{~h}$. In this period of the light/dark cycle, rats have the highest amount of spike-wave discharges (van Luijtelaar and Coenen, 1988).

Nimodipine and Bay K 8644 (Bayer, Germany) were given intraperitoneally (i.p.) in a volume of 2 $\mathrm{ml} / \mathrm{kg}$ body weight as a freshly ultrasonicated solution in a mixture of solutol/ethanol/ $0.9 \% \mathrm{NaCl}$ (5:5:90). The solution was prepared in a dark room and shielded from light. Animals were divided into seven groups, each consisting of 7-10 rats. They were connected to the recording leads $16 \mathrm{~h}$ before EEG recordings were made. Nimodipine was injected in dosages of $2.2,8.8$ and $35.2 \mathrm{mg} / \mathrm{kg}$; Bay K 8644 was administered in dosages of $0.12,0.47$ and $1.88 \mathrm{mg} / \mathrm{kg}$. In addition, we established a control group by injecting rats with solvent. After a 1-h baseline EEG recording, animals were injected i.p. with drugs or solvent. Subsequently, the EEG was recorded for 2 consecutive $h$.

The EEG signal was amplified and filtered by an Elema-Schönander polygraph and frequencies between 1 and $70 \mathrm{~Hz}$ were allowed to pass. The EEG was subsequently stored in digitized form on a magnetooptical disk (DATA Instruments, AT-CODAS). Spike-wave discharges were visually scored according to criteria described previously (van Luijtelaar and Coenen, 1986). The number of spike-wave discharges and total duration of individual episodes of spike-wave discharges were determined by one of us (N.A.). Examples of spike-wave discharges are shown in Fig. 1. The number and duration of the spike-wave discharges were calculated for the baseline hour and for the four postinjection 30-min periods.

Spontaneous behavior of the rats in their cages was closely observed through a window from an adjacent room. We quantified duration of the following behavioral categories for $30 \mathrm{~min}$, beginning 5 min after injection: exploratory behavior (walking, rearing, sniffing, digging), automatic behavior (grooming, eating, drinking), and immobile behavior (sitting, lying, and standing still) (Coenen and van Luijtelaar, 1989). Data were recorded and analyzed with a PC registration software package (The Observer, Wageningen, NL) (Noldus, 1991). All data were statistically verified by analysis of variance (ANOVA), followed by Duncan's post hoc test for multiple comparisons.

\section{RESULTS}

All rats showed predrug spontaneously occurring spike-wave discharges in their cortical EEG, and most of the spike-wave discharges occurred during passive behavior. Sample records of EEGs containing spike-wave discharges made before and after nimodipine and BAY K 8644 administration are shown in Fig. 1a and b. The effects of nimodipine on spike-wave discharges are shown in Fig. 2. There were no differences between the four groups before injection. Nimodipine induced an increase in number of spike-wave discharges in the first and fourth 30-min period after injection $(F=4.02, \mathrm{p}<$ 0.05 and $F=5.20, \mathrm{p}<0.01$ respectively; both $d f$ 3,28 ): post hoc tests showed that at $0-30$ min after- 


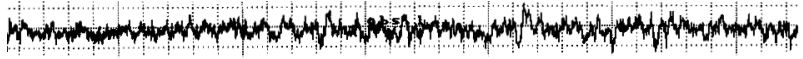

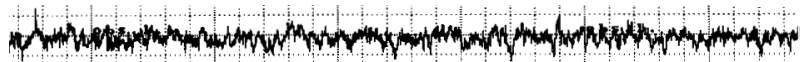
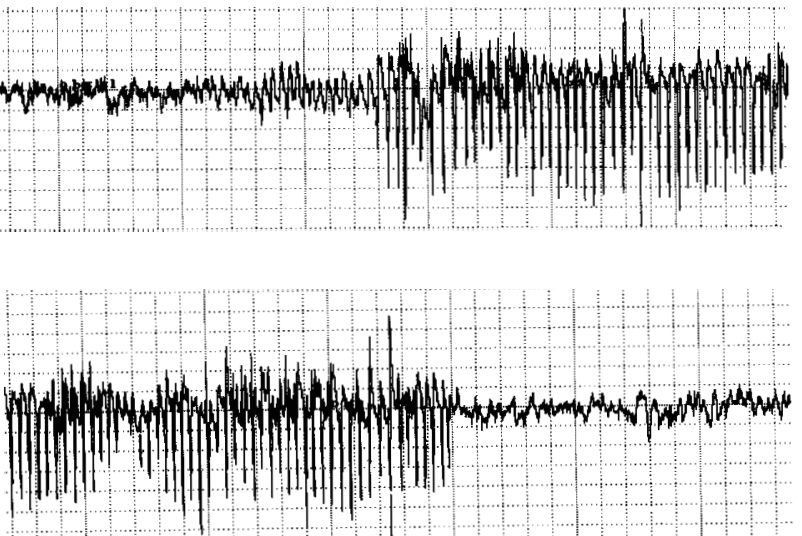

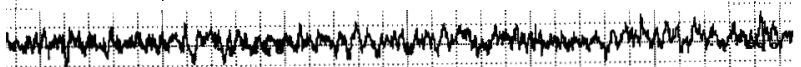

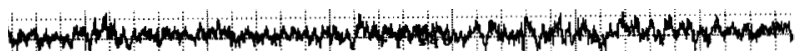
I... $100 \mu \mathrm{V}$

$1 \mathrm{sec}$

$1 b$

PRE-DRUG

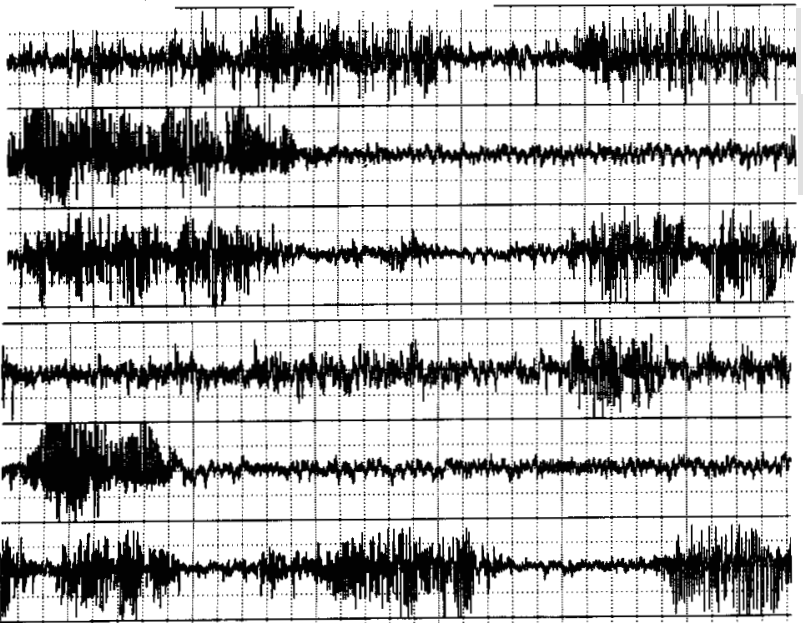

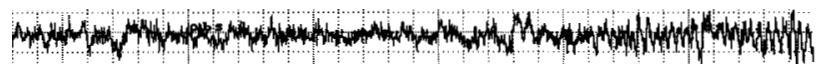
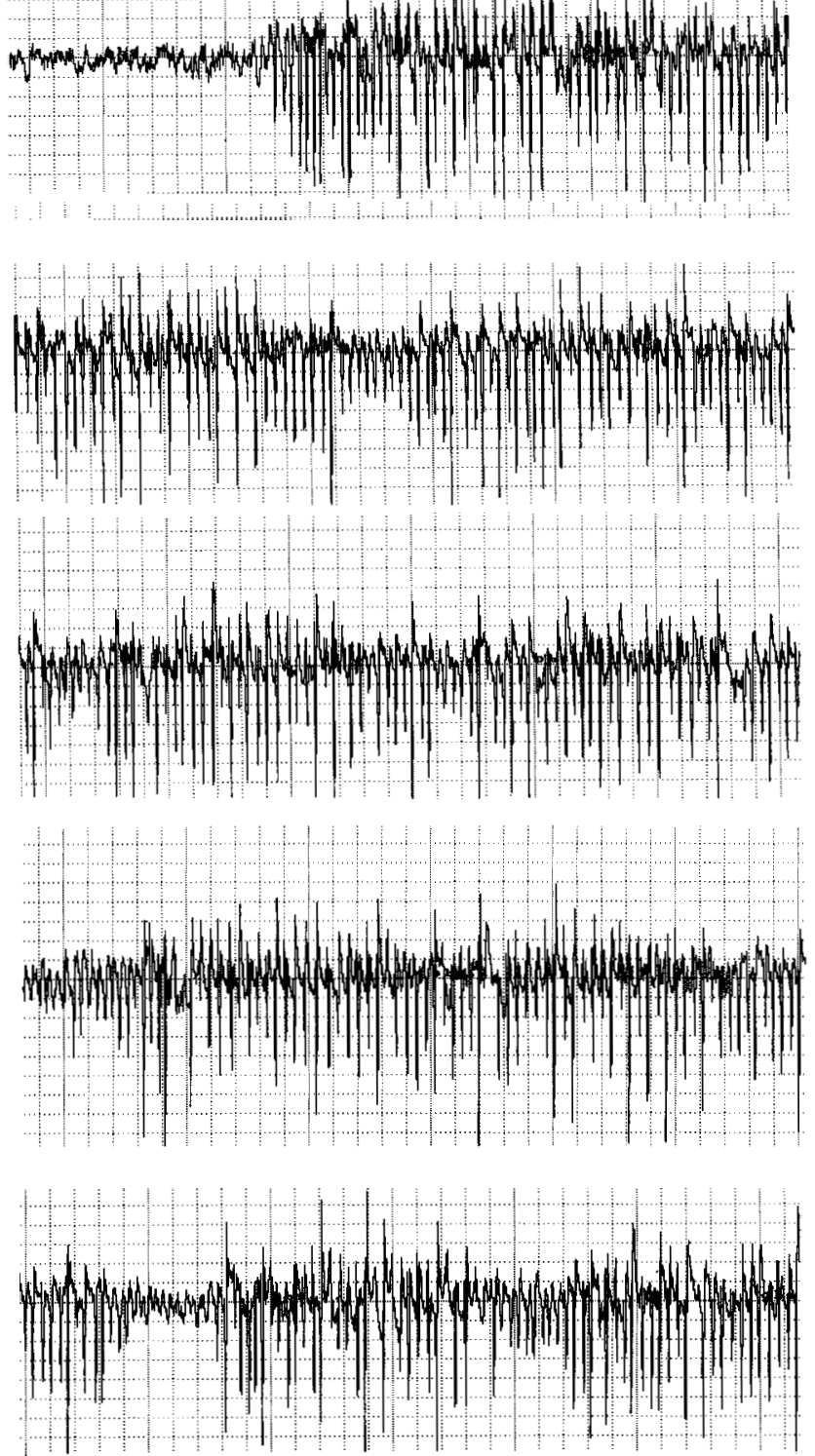

POST-DRUG

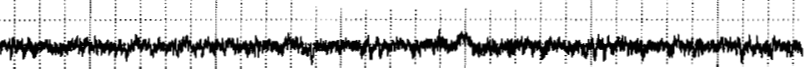

r.w.

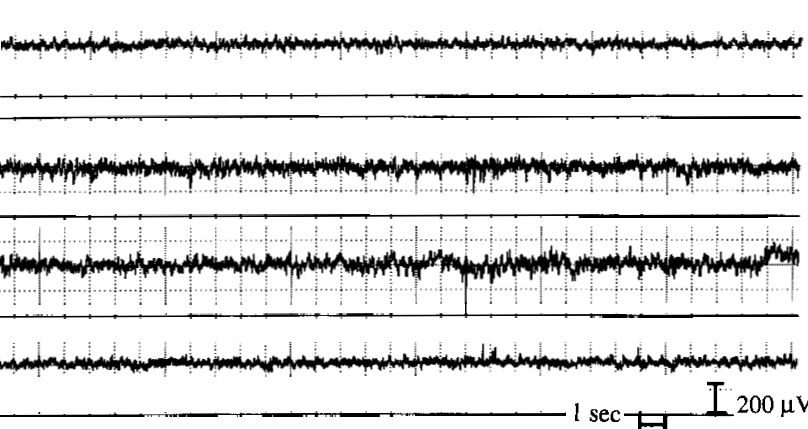


injection the group receiving $35.2 \mathrm{mg} / \mathrm{kg}$ nimodipine had significantly more spike-wave discharges than the other three groups. The same groups also differed 90-120 min postinjection. The pooled data 0 120 min postinjection showed a significant dose effect $(F=3.53$, df 3,28, $\mathrm{p}<0.05)$; again, the 35.2$\mathrm{mg} / \mathrm{kg}$ group showed more spike-wave discharges than the three other groups.

A significant dose effect was noted for total duration of spike-wave discharges in the first, third, and fourth 30 -min period after injection $(F=4.35$, $\mathrm{p}<0.05 ; F=3.52, \mathrm{p}<0.05 ;$ and $F=8.59, \mathrm{p}<$ 0.001 respectively; all $d f 3,28)$. Post hoc tests showed that $0-30 \mathrm{~min}$ after administration the duration of the discharges was increased in the 35.2$\mathrm{mg} / \mathrm{kg}$ nimodipine group as compared with the other two nimodipine groups and that during the 60-90min period the duration in the $35.2-\mathrm{mg} / \mathrm{kg}$ group was increased as compared with that of the $2.2-\mathrm{mg} / \mathrm{kg}$ group; finally, during the 90-120-min period, duration of the spike-wave discharges after the highest dose was still enhanced as compared with that of the three other groups.

Nimodipine induced a change in exploratory ( $F$ $=3.07, d f 3,27, \mathrm{p}<0.05)$ and immobile behavior $(F$ $=4.16$, df $3,27, \mathrm{p}<0.05$ ). Rats that received 2.2 $\mathrm{mg} / \mathrm{kg}$ drug showed significantly less exploratory and more immobile behavior than control rats. Animals that received $35.2 \mathrm{mg} / \mathrm{kg}$ nimodipine also showed more immobile behavior than the control group.

Results obtained after administration of Bay $\mathrm{K}$ 8644 are shown in Fig. 3. There were no differences between the groups before injection, but there were clear effects of BAY K 8644 after administration. Bay K 8644 had significant effects in all four 30-min periods after drug administration on the number of spike-wave discharges $(F=6.23$, df $3,30, \mathrm{p}<0.01$; $F=11.99$, df $3,29, \mathrm{p}<0.0001 ; F=6.98, d f 3,28$, $\mathrm{p}<0.01 ; F=4.25, d f 3,27, \mathrm{p}<0.05$ respectively). Post hoc tests showed that in all four 30-min periods the $1.88-\mathrm{mg} / \mathrm{kg}$ group had less spike-wave discharges than the $0.12-\mathrm{mg} / \mathrm{kg}$ group or the control goup and that the $0.47-\mathrm{mg} / \mathrm{kg}$ group had fewer spike-wave discharges than the control group. The $0.12-\mathrm{mg} / \mathrm{kg}$ BAY K 8644 group also had fewer spike-wave discharges $30-90 \mathrm{~min}$ postinjection as compared with the control group. In all, a clear dose-dependent decrease was noted in the number of spike wave discharges.

BAY K 8644 also had significant effects on total duration of spike-wave discharges in all four 30-min periods $(F=5.26, d f 3,30, \mathrm{p}<0.01 ; F=6.65, d f$ $3,29, \mathrm{p}<0.01 ; F=3.68$, df $3,28, \mathrm{p}<0.05 ; F=$ 3.86 , df $3,27, \mathrm{p}<0.05$, respectively). Post hoc tests showed that in all four 30-min postinjection periods the duration of the spike-wave discharges was shorter after $1.88 \mathrm{mg} / \mathrm{kg}$ BAY K 8644 as compared with saline and that $0-60$ min postinjection total duration was also less in rats that had received 0.47 $\mathrm{mg} / \mathrm{kg}$ as compared with saline. Finally, 30-60 min postinjection, duration of the $1.88-\mathrm{mg} / \mathrm{kg}$ group was also reduced as compared with that of the $0.47-\mathrm{mg} /$ $\mathrm{kg}$ group and total duration of the $0.12 \mathrm{mg} / \mathrm{kg}$ group was reduced as compared with saline. In all, dose dependency on total duration is strongly suggested by our data.

Bay K 8644 increased the number of immobile ( $F$ $=4.87, d f 3,24, \mathrm{p}<0.01)$ and exploratory $(F=$ 5.57 , df $3,24, \mathrm{p}<0.01)$ periods at the highest dose only, without affecting total and mean duration of these behavioral categories. After the highest dose, only some animals showed signs of ataxia. Three of the 10 animals that had received $1.88 \mathrm{mg} / \mathrm{kg} \mathrm{BAY} \mathrm{K}$ 8644 had fatal convulsions $35-95$ min postinjection. Convulsions never occurred in the three other groups. The data on number and duration of discharges in these animals were included until the convulsions appeared on EEG.

\section{DISCUSSION}

All old rats exhibited spike-wave discharges. The discharges were of the same type and morphology described by other investigators in selection lines [in particular the Strasbourg Wistar rats (Vergnes et al., 1982)] or inbred [in particular the WAG/Rij strain (van Luijtelaar and Coenen, 1986)] or outbred strains of rats (Willoughby and Mackenzie, 1992). The number and mean duration of these discharges agreed with previous results obtained in the same outbred strain (van Luijtelaar et al., 1994). We studied only changes in number and duration of spikewave discharges; we did not quantify clinical phenomena that accompany the spike-wave discharges in rats as in humans. Recently, we attempted to evaluate the most characteristic property of ab-

FIG. 1. a: Sample recording of cortical EEG of $(\sim 1 \mathrm{~min})$ of 1 rat predrug (left) and of 1 min 20 min after administration of 35.2 $\mathrm{mg} / \mathrm{kg}$ nimodipine (right). A spike-wave discharge lasting $\sim 8 \mathrm{~s}$ is apparent predrug. Postdrug, a long train with almost continuous spike-wave activity is evident. b: Sample recordings of cortical EEGs of three different rats ( $\sim 1 \mathrm{~min})$ predrug (left) and ( $\sim 1 \mathrm{~min})$ postdrug (right) $(1.88 \mathrm{mg} / \mathrm{kg} \mathrm{BAY} \mathrm{K} \mathrm{8644).} \mathrm{First} \mathrm{and} \mathrm{fourth} \mathrm{tracing} \mathrm{are} \mathrm{from} \mathrm{the} \mathrm{same} \mathrm{rat,} \mathrm{as} \mathrm{are} \mathrm{the} \mathrm{second} \mathrm{and} \mathrm{fifth} \mathrm{and} \mathrm{the} \mathrm{third}$ and sixth. Predrug spontaneously occurring spike-wave discharges were abundant; very few occurred after BAY K 8644 . Time scales and calibration values are different in $a$ and $b$. Different scales were chosen for illustration purposes only. 
sences, the decrease in responsiveness, in humans and in rats. In a time-estimation paradigm, both species showed a loss of perceived time in trials with spike-wave discharges, suggesting that in both humans and rats the spike-wave discharges are accompanied by similarities in decrease in consciousness (van Luijtelaar et al., 1991 $a ; 1991 b$ ). This finding contributes to the validation of spike-wave discharges in rats as a model for human absence epilepsy.

Our present results demonstrate that the calcium antagonist nimodipine tends to increase the number and total duration of spike-wave discharges in this model of nonconvulsive epilepsy. The effects of nimodipine on overt behavior were mild; only an increase in passive behavior was noted. Mack and Gilbert (1992) noted no overt changes in rat behavior after administration of $50 \mathrm{mg} / \mathrm{kg}$ nimodipine; De Sarro et al. (1990), using $70.2 \mathrm{mg} / \mathrm{kg}$, noted a reduction in locomotor activity, mild ataxia, piloerection, and sedation only at that dose. The highest dose of nimodipine we used was higher than that commonly used to produce cardiovascular actions, and a decrease in systemic blood pressure is common after systemic application of this dose of nimodipine, which may in turn induce behavioral immobility; considering the well-known relation between mental and physical activity on the one hand and spikewave discharges (Coenen et al., 1991; Drinkenburg et al., 1991; van Luijtelaar et al., 1991b) on the other, one may assume that the increase in number of spike-wave discharges results from the increase in behavioral immobility induced by hypotension. However, two factors are not in accord with this notion. First, some sedation also was evident after the lowest dose of nimodipine and was not associated with an effect on spike-wave discharges. Second, the increase induced by the antagonist is in accord and consistent with the decrease induced by the agonist. From the present experiment, we conclude that Bay K 8644 reduces spike-wave dis-

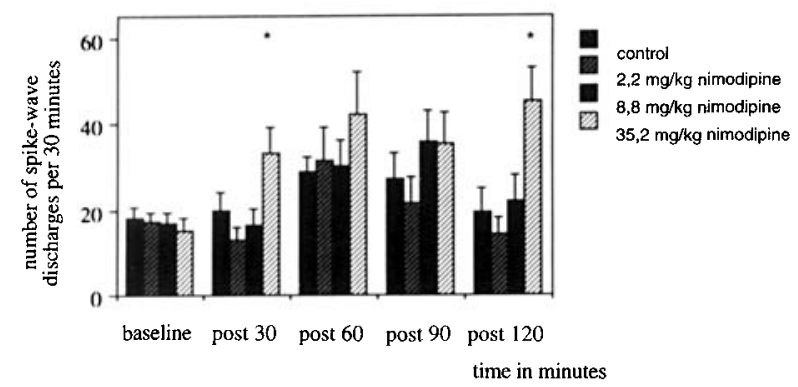

FIG. 2. Number of spike-wave discharges (mean and SEM) during baseline and during four 30 -min periods after intraperitoneal administration of various doses of nimodipine $(2.2,8.8$, and $35.2 \mathrm{mg} / \mathrm{kg})$ and solvent.

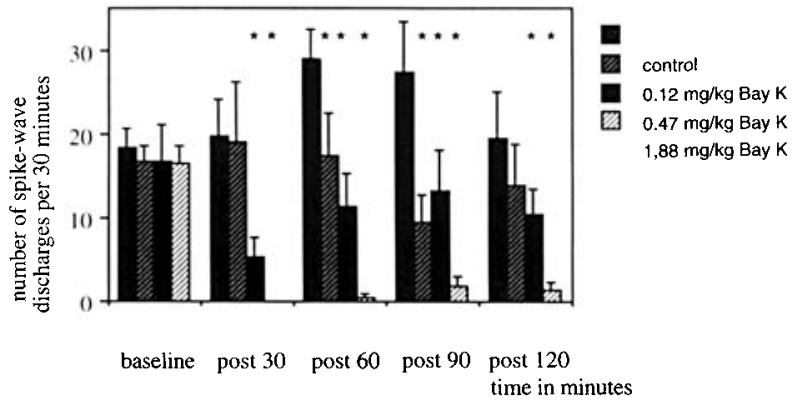

FIG. 3. Number of spike-wave discharges (mean and SEM) during baseline and during four 30 -min periods after intraperitoneal administration of various doses $(0.12,0.47$, and $1.88 \mathrm{mg} / \mathrm{kg}$ ) of BAY K 8644 and solvent.

charges dose dependently. The effects of Bay $\mathrm{K}$ 8644 on behavior were evident only at the highest dose; animals changed their behavior more often. Duration of the various behavioral categories was not changed, nor were there abnormal behavioral patterns such as ataxia (except in 2 animals) with splayed hind legs, delay in the righting reflex, arching back, and tremor. Such a pattern was described in GEPR rats after a much higher dose of BAY $\mathrm{K}$ 8644 than that used in the present study (De Sarro et al., 1990). Because the mild effects on behavior were evident only after the highest dose and the effects on the number of spike-wave discharges was already apparent at the lowest dose, the antiepileptic action of BAY K 8644 probably is not due to its behavioral-activating effects.

The protective effects of BAY K 8644 and the facilitatory effects of nimodipine were contrary to effects previously described indicating that calcium antagonists act like AEDs (Ashton and Wauquier, 1979; Hoffmeister et al., 1982; Drago et al., 1986; Heinemann and Hamon, 1986; Hoffmeister and Tetterhorn, 1986; Meyer et al., 1986,1987; De Sarro et al., 1988; Yuasa et al., 1989; Kamal et al., 1990). Moreover, agonists or channel activators such as BAY K 8644 act like convulsant drugs (De Sarro et al., 1990). A closer look at the type and nature of the experiments cited shows that calcium antagonists are mainly effective in models for complex partial and generalized tonic-clonic seizures and also that agonists promote convulsions. De Sarro et al. (1990) reported that 4 of 10 GEPR showed clonic and tonic convulsions and, with the same dose, fatal convulsions indeed occurred after BAY K 8644 in the present experiment: 3 of 10 animals died after a convulsion. The near-complete blockade of spikewave discharges and the increased probability for seizures in the same animal demonstrates that BAY K 8644 combines two actions: a proconvulsant action in convulsive epilepsy and an antiepileptic action in nonconvulsive epilepsy. It is of interest that such a two-way action of BAY K 8644 is also de- 
scribed for $\alpha_{2}$-adrenergic agonists and GABA agonists. Such drugs also promote spike-wave discharges and inhibit convulsions. Overall, these actions demonstrate that opposite mechanisms are involved in convulsive and nonconvulsive epilepsy (Buzsáki et al., 1991; Coenen et al., 1992).

Spike-wave discharges are believed to result from interplay of thalamic oscillator and a reciprocal connection of thalamic and cortical neuronal populations. Thalamic rhythmicy is considered to originate from the reticular thalamic nucleus (Steriade and Buzsáki, 1990) or from an interaction of dorsal lateral parts and the reticular part of the thalamus (Buzsáki, 1991). The rhythmic bursting of thalamic neurons is specifically dependent on the T-type calcium channel, as demonstrated by many in vitro studies (Jahnsen and Llinás, 1984; Steriade and Llinás, 1988; Coulter et al., 1990; Avanzini et al., 1992). Suzuki and Rogawski (1989) showed that these thalamic oscillations could be blocked by T-type calcium channel blockers. Coulter et al. confirmed the involvement of T-type channels in oscillations and in absence epilepsy by showing that ESM, a drug that selectively protects against absence epilepsy, specifically inhibits T-type channels (Coulter et al., 1989a,1989b); thus ample evidence shows that T-type calcium channel blockade inhibits thalamic oscillations. The present results show opposite effects: L-type calcium channel opening inhibits spike-wave discharges and L-type calcium channel blockade tends to facilitate spike-wave discharges.

Nimodipine may not modulate calcium channels exclusively. Nimodipine may block sodium and glutamate as well as calcium-dependent potassium and chloride channels in a dose range that modulates epilepsy (Jones and Heinemann, 1987; Aicardi et al., 1990). Avanzini et al. (1992) suggested that blockade of calcium channels is the mechanism underlying inhibition of spike-wave discharges. They showed that cadmium, which blocks both the calcium and the calcium-dependent potassium channels, suppressed repetitive burst discharges in vitro and decreased the number of spike-wave discharges in vivo. However, application of cadmium does not indicate whether blockade of calcium or blockade of calcium-dependent potassium channels is the main factor; whether nimodipine aggravates spikewave discharges by blocking sodium, glutamate, or the calcium-dependent potassium channels should be investigated. A role for potassium channels in nonconvulsive epilepsy is supported by the results of Gandolfo et al. (1989), who showed that a potassium channel opener reduces spike-wave discharges in vivo.
Our results demonstrate that L-type calcium channel blockade facilitates and opening of the L-type channels suppresses spike-wave discharges. We propose a differential and diametrically opposite role of T- and L-type calcium ions in absence epilepsy: Blockade of the T-type and activation of the L-type calcium channels reduces spike-wave activity, and activation of the T-type and blocking of the L-type channels facilitates spike-wave activity. Finally, L-type modulation apparently differs in convulsive and in nonconvulsive epilepsy.

Acknowledgment: Rats and drugs were donated by Drs. F. J. van der Staay and T. Schuurman, Institute for Neurobiology, Troponwerke, Köln, Germany. We thank Professor Dr. U. Heinemann and Dr. H. Luhmann, Department of Physiology, University of Köln for their contribution to the discussion.

\section{REFERENCES}

Aicardi G, Schwartzkroin PA. Suppression of epileptiform burst discharges in CA3 neurons of rat hippocampal slices by the organic calcium channel blocker, verapamil. Exp Brain Res 1990;81:288-96.

Ashton D, Wauquier A. Effects of some anti-epileptic, neuroleptic and gabaminergic drugs in convulsions induced by $\mathrm{D}, \mathrm{L}-$ allyglycine. Pharmacol Biochem Behav 1979;11:221-6.

Avanzini G, de Curtis M, Marescaux C, et al. Role of the thalamic reticular nucleus in the generation of rhythmic thalamocortical activities subserving spike and waves. $J$ Neural Trans 1992;S35:85-95.

Bernath S. Calcium independent release of amino acid neurotransmitters; fact or artifact? Prog Neurobiol 1992;38:57-80.

Buzsáki $\mathrm{G}$. The thalamic clock: emergent network properties. Neuroscience 1991;41:351-64.

Buzsáki G, Kennedy B, Solt VB, et al. Noradrenergic control of thalamic oscillation: the role of $\mathrm{a}_{2}$ receptors. Eur J Neurosci 1991;3:222-9.

Coenen AML, van Luijtelaar ELJM. Effects of diazepam and two beta-carbolines on epileptic activity and on EEG and behavior in rats with absence seizures. Pharmacol Biochem Behav 1989;32:27-35.

Coenen AML, Drinkenburg WHIM, Inoue M, et al. Genetic models of absence epilepsy, with emphasis on the WAG/Rij strain of rats. Epilepsy Res 1992;12:75-87.

Coenen AML, Drinkenburg WHIM, Peeters BWMM, et al. Absence epilepsy and the level of vigilance in rats of the WAG/ Rij strain. Neurosci Biobehav Rev 1991;15:259-63.

Coulter DA, Huguenard JR, Prince DA. Characterization of ethosuximide reduction of low-threshold calcium current in thalamic neurons. Ann Neurol 1989a;25:582-93.

Coulter DA, Huguenard JR, Prince DA. Specific petit mal anticonvulsants reduce calcium currents in thalamic neurons. Neurosci Lett 1989b;98:74-8.

Coulter DA, Huguenard JR, Prince DA. Differential effects of petit mal anticonvulsants and convulsants on thalamic neurons; calcium current reductions. Br J Pharmacol 1990;100: $800-6$.

Crowder JM, Bradford HF. Common anticonvulsants inhibit $\mathrm{Ca}^{2+}$ uptake and amino acid concentration release in vitro. Epilepsia 1987;28:378-82.

De Sarro GB, Meldrum BS, Nistico G. Anticonvulsant effects of some calcium entry blockers in DBA/2 mice. Br J Pharmacol 1988;93:247-56.

De Sarro G, De Sarro A, Federico F, et al. Anticonvulsant properties of some calcium antagonists on sound-induced seizures 
in genetically epilepsy prone rats. Gen Pharmacol 1990;21: 769-78.

Drago F, Valerio C, Clementi G, et al. Effects of flunarizine on experimentally-induced convulsions in animals. Funct $\mathrm{Neu}$ rol 1986;1:529-32.

Drinkenburg WHIM, Coenen AML, Vossen JMH, et al. Spikewave discharges and sleep-wake states in rats with absence epilepsy. Epilepsy Res 1991;9:218-24.

Gandolfo G, Romettino S, Gottesmann C, et al. $\mathrm{K}^{+}$Channel openers decrease seizures in genetically epileptic rats. Eur $J$ Pharmac 1989;167:181-3.

Heinemann U, Hamon B. Calcium and epileptogenesis. Exp Brain Res 1986;65:1-10.

Heinemann U, Lux HD, Gutnick MJ. Extracellular free calcium and potassium during paroxsysmal activity in the cerebral cortex of the cat. Exp Brain Res 1977;27:237-43.

Hoffmeister F, Tetterhorn D. Calcium agonists and antagonists of the dihydropyridine type: antinociceptive effects, interference with opiate- $\mu$-receptor agonists and neuropharmacological actions in rodents. Psychopharmacology 1986;90:299 307.

Hoffmeister F, Benz U, Heise A, et al. Behavioural effects of nimodipine in animals. Arzneimittelforschung Drug Res 1982; 32:347-60.

Jahnsen $\mathrm{H}$, Llinás R. Ionic basis for the electro-responsiveness and oscillatory properties of guinea-pig thalamic neurons in vitro J Physiol 1984;349:227-47.

Jones RSG, Heinemann UH. Differential effects of calcium entry blockers on pre- and postsynaptic influx of calcium in the rat hippocampus in vitro. Brain Res 1987:416:257-66.

Kamal JA, Nadig RS, Thangam J, et al. Effect of calcium channel blockers on experimentally induced seizures in rats. Indian J Exp Biol 1990;28:605-8.

Mack, CM, Gilbert ME. An examination of the anticonvulsant properties of voltage-sensitive calcium channel inhibitors in amygdala kindles seizures. Psychopharmacology 1992;106: 365-9.

Meyer JS. Nimodipine is effective in prophylactic treatment of migraine and cluster headaches. In: Betz E, Dech K, Hoffmeister F, eds. Nimodipine pharmacological and clinical properties. Proceedings of the 1 st international Nimotop symposium, Munich, Germany, Stuttgart: Schattauer Verlag, 1985:431-41.

Meyer FB, Anderson RE, Sundt TM, et al. Suppression of pentylenetetrazole seizures by oral administration of dihydropyridine $\mathrm{Ca}^{2+}$ antagonist. Epilepsia 1987;28:409-14.

Meyer FB, Tally PW, Anderson RE, et al. Inhibition of electrically induced seizures by a dihydropyridine calcium channel blocker. Brain Res 1986;384:180-3.

Noldus LPJJ. The observer: a software system for collection and analysis of observational data. Behav Res Methods Instru Comput 1991;23:415-29.
Peeters BWMM, Spooren WPJM, van Luijtelaar ELJM, et al. The WAG/Rij model for absence epilepsy: anticonvulsant drug evaluation. Neurosci Res Commun 1988;2:93-7.

Sills GJ, Carswell A, Brodie MJ. Dose-response relationships with nimodipine against electroshock seizures in mice. Epilepsia $1994 ; 35: 437-42$.

Speckmann EJ, Walden J. Suppression of focal and generalized tonic-clonic seizures by a calcium antagonist in the rat. In: Manelis J, Bental E, Loeber JN, Dreifuss FE, eds. Advances in epileptology, vol. 17. New York: Raven Press, 1989:115-8.

Spedding M, Paoletti R III. Classification of calcium channels and the sites of action of drugs modyfying channel function. Pharmacol Rev 1992;44:363-76.

Steriade M, Buzsáki G. Parallel activation of thalamic and cortical neurons by brainstem and basal forebrain cholinergic systems. In: Steriade M, Biesold D, eds. Brain cholinergic systems. Oxford: Oxford Medical Press, 1990:3-64.

Steriade M, Llinás RR. The functional state of the thalamus and the associated neuronal interplay. Physiol Rev 1988;68:649742.

Suzuki S, Rogawski MA. T-Type calcium channels mediate the transition between tonic and phasic firing in thalamic neuron. Proc Natl Acad Sci USA 1989;86:7228-32.

van Luijtelaar ELJM, Coenen AML. Circadian rhythmicity in absence epilepsy in rats. Epilepsy Res 1988;2:331-6.

van Luijtelaar ELJM, Coenen AML. Two types of electrocortical paroxysms in an inbred strain of rats. Neurosci Lett 1986; 70:393-7.

van Luijtelaar ELJM, Ates N, van der Staay FJ. The effects of subchronic treatment with a calcium channel antagonist on two types of generalized epilepsies in rats. Pharmacol Biochem Behav 1994;48:575-9.

van Luijtelaar ELJM, De Bruijn SFTM, Declerck AC, et al. Disturbances in time estimation during absence seizures in children. Epilepsy Res 1991a;9:148-53.

van Luijtelaar ELJM, Van de Werf SJ, Vossen JMH, et al. Arousal, performance and absence seizures in rats. Electroencephalogr Clin Neurophysiol 1991b;79:430-4.

Vergnes M, Marescaux C, Micheletti G, et al. Spontaneous paroxysmal electroclinical patterns in rat: a model of generalized non-convulsive epilepsy. Neurosci Lett 1982;33:97-101.

Willoughby JO, Mackenzie L. Nonconvulsive electrocorticographic paroxysms (absence epilepsy) in rat strains. Lab Anim Sci 1992;42:551-4.

Yaari Y, Hamon B, Lux HD. Development of two types of calcium channels in cultured hippocampal neurons. Science $1987 ; 235: 680-2$.

Yuasa H, Iwata K, Yamada T, et al. Effects of some $\mathrm{Ca}^{2+}$ antagonists on interictal spikes of hippocampal slices. In: Manelis J, Bental E, Loeber JN, Dreifuss FE, eds. Advances in epileptology, vol. 17. New York: Raven Press, 1989:142-6. 